\title{
HEIDEGGER E AS CIÊNCIAS
}

\section{Nuno Melim}

Heidegger $e$ as ciências. Eis, aparentemente, uma conjunção problemática. Problemática porque segundo alguns há em Heidegger um certo «anticientismo": "[...] ele é contra as ciências!" Exclamação previsível mas, em nosso entender, infundada, se pensarmos que Heidegger chegou até a considerar a ciência como um fenómeno essencial dos tempos modernos ${ }^{2}$. Perguntamos simplesmente: Heidegger é contra as ciências? Que significará esse conträ?

No que se segue pretendemos apenas tecer algumas considerações acerca da concepção heideggeriana de ciência, mostrando também que não há um «anticientismo», uma «aversão» face às ciências, mas antes um pensamentô crítico.

\section{Ontologia e ciências}

Tentemos, pois, compreender $\bullet$ que Heidegger nos diz acerca das ciências. Comecemes por relacionar estas com a filosofia, com a ontologia. Se perguntarmos 'o que é a ciência?', uma das respostas poderia ser:

"Demos apenas como fio condutor esta definição formal de ciência: a ciência é o desvelamento constitutivo de um domínio em si fechado do ente, quer dizer, do ser; desvelamento que tem por fim a sua própria realização. Cada domínio de objectos tem, segundo o carácter e a maneira de ser dos seus

'A exclamação é de Prigogline: "Na sua passagem por Lisboa, no outono de 1988, quando the falei de Heidegger, Prigogine não teve senão esta resposta muito previsivel: «mas ele é contrā as ciềncias!"” (Cf. Fermando Belo, Le Jeu des Sciences avec Heidegger; Derrida et Prigogine - Retrait et régulation de l'aléatoire, Lisboa, 1997, p. 47, nota 29 - texto não publicado)

${ }^{2}$ Vide Heidegger, "Die Zeit des Weltbildes", "L'époque des conceptions du monde" in Holzwege. Chemins qui ne mènent nulle part, tad. Wolfgang Brokmeier, Paris, Gallimard, 1962, p. 99.

Phainomenon, n. ${ }^{0} 3$, Lisboa, Edições Colibri, 2001, pp. 43-55

DOI: 10.2478/phainomenon-2001-0009 
objectos, um modo próprio de desvelar, mostrar, fundar e marcar conceptualmente o conhecimento que assim se forma." ${ }^{3}$

Atentando nesta definição, vislumbramos, entre outras coisas, a famosa associação entre ser e ente, bem como a relação entre as ciências e a ontologia. O ser, diz Heidegger, é sempre ser dos entes. Há um universo de entes que abarca sectores ou domínios distintos, como por exemplo: a história, a natureza, o espaço, a vida, o homem, a linguagem, etc.. Esses sectores são «libertos», tematizados, pelas investigações científicas que constituem tais domínios como «objectos» de conhecimento ${ }^{4}$.

As ciências como que estudam «repartições» no imenso e quase insondável «ministério» do ser. Desta maneira, podem ser enquadradas no âmbito do projecto daquilo a que Heidegger chama «ontologia fundamental», porquanto são "o desvelamento de um domínio em si fechado do ente ou do ser"; isto é, podem ser consideradas «ontologias regionais». Todavia, ontologia fundamental e ontologias regionais têm as suas diferenças (tal como as ontologias regionais têm diferenças entre si): não se dirigem ao mesmo objecto do mesmo modo, não têm o mesmo método (o "modo próprio de..."), a mesma maneira de proceder.

Entre ontologia e ciências há um jogo de olhares em que devemos atentar:

"A ideia de ciência em geral, na medida em que a concebemos como possibilidade do Dasein, mostra que, em princípio, há necessariamente dois tipos de ciência: a ciência do ente, a ciência ôntica, e a ciência do ser, a ciência ontológica, a filosofia. [...] A ciência do ser, a ontologia, necessita fundamentalmente de uma inversão do olhar dirigido para o ente: o olhar vira-se do ente para o ser, mas o ente permanece objecto do olhar." ${ }^{\text {, }}$

${ }^{3}$ Heidegger, "Phaenomenologie und Theologie". "Phénomenologie et Théologie" in Archives de Philosophie vol.32, trad. Marcel Méry, Paris, Beauchesne, 1969, p. 359. Notemos que esta definição muito formal de ciência não tem em consideração as diferenças existentes entre os vários tipos de ciências. Como veremos, há basicamente dois tipos de ciência: as ciências ônticas, nas quais poderemos encontrar, por exemplo, as «ciências da natureza» e as «ciências do espírito», e a ciência ontológica (a filosofia).

${ }^{4}$ Cf. Heidegger, Sein und Zeit El ser y el tiempo, trad. José Gaos, México, Fondo de Cultura Económica, 195, §3, p. 18.

${ }^{5}$ Heidegger, "Phaenomenologie und Theologie", trad. cit., p. 359. Notemos que posteriormente a ontologia não será vista como uma «ciência». Digamos ainda que a diferença entre ontologias regionais e ontologia fundamental pode ser vista também quanto aos seus modos de interrogação: as primeiras partiriam (efectivamente) de um questionar exclusivo; a segunda de um questionar inclusivo, no qual o todo é colocado em questão, inclusive aquele que questiona enquanto questiona (cf. Die Grundbegriffe der Metaphysik. Welt-Endlichkeit-Einsamkeit. Les Concepts Fondamentaux de la Métaphysique, trad. Daniel Panis, Paris, Gallimard, 1992, $\$ 3$, p. 27. e $\$ 7$, p. 48.). Esta diferença parece-nos pertinente, até porque Heidegger a retomará, em certo sentido, quando distingue pensamento que medita - 
A tarefa da ontologia fundamental, diz Heidegger, é despertar a atenção para a questão que interroga pelo sentido do ser: "Destacar o ser dos entes e explicar o próprio ser é o problema da ontologia." " A ontologia fundamental estudaria ambas as conjuntas da conjunção ser e ente, ao invés das ciências, que apenas estudam efectivamente uma das conjuntas (o ente).

Para cumprir a sua tarefa, a ontologia tem a sua «maneira de proceder», fenomenológica e hermenêutica, que se executa em três fases: a redução, quando passa dos entes para o seu ser (por exemplo, passar das ciências empíricas para as ontologias regionais e depois para a ontologia fundamental a «inversão do olhar» supracitada); a construção, que consiste na projecção dos entes para as suas estruturas ontológicas; a destruição, que elabora o desmantelamento dos conceitos historicamente transmitidos em que o ser é habitualmente descrito, de modo a remontar às fontes de que foram tirados ${ }^{7}$.

Ontologia e ciências diferem no método e no objecto. Ao perguntarmos pelo sentido do ser, e para prepararmos uma resposta, temos de elucidar um «lugar», um «aí», a partir do qual o ser é questionado e já compreendido. A ontologia fundamental começa e, ao que parece, quedou-se numa analítica existenciária do Dasein (o insigne ente ôntico-ontológico), desse ente que tem uma relação privilegiada com o ser e uma referência à própria pergunta que interroga pelo ser, dado que é o único ente capaz de a colocar. O Dasein existe essa questão, se assim nos podemos expressar; responde (nem sempre temática ou expressamente) a essa questão existindo.

Mas, o que é importante reter, no contexto em que nos debruçamos, é que ao esclarecer as estruturas existenciárias do Dasein, a ontologia esclarece as condições de possibilidade de algo como «as ciências» ${ }^{8}$.

que reflecte sobre si próprio - de pensamento que calcula - que não pode reflectir sobre si próprio ("A Física, enquanto Física, não pode dizer nada sobre a Física. [...] Não poderemos nunca, por um cálculo matemático, decidir o que é a própria matemática”, Heidegger, "Science et méditation" in Vorträge und Aufsätze. Essais et Conférences, trad. André Préau, Paris, Gallimard, 1958, p. 73. Cf. ainda Heidegger, "Gelassenheit"."Serenité” in Questions III, trad. André Préau, Paris, Gallimard, 1966, pp. 159-181. e Gadamer, H.-G., Wahrheit und Methode. Vérité et Méthode, trad. Pierre Fruchon, Jean Grondin et Gilbert Merlio, Paris, Seuil, 1996, p. 476.). A diferença entre ontologia (filosofia) e ciências, quanto ao modo de questionar, não será polémica ou chocante, não implicará um «anticientismo», se admitirmos que na actividade científica, como dizem investigadores mais ligados às ciências, não devemos levantar todas as questões envolvidas num problema científico; pelo contrário, devemos limitar o número de questões a resolver e considerar apenas alguns fenómenos (cf. Sambursky, "The world of the atom" in The Physical World of the Greeks, London, Routledge, 1956, p. 112.).

${ }^{6}$ Heidegger, Sein und Zeit, trad. cit., \$7, p. 37.

${ }^{7}$ Cf. Heidegger, Prolegomena zur Geschichte des Zeitbegriffs. History of the concept of Time, trad. Theodore Kisiel, Bloomington and Indianapolis, Indiana University Press, 1985, p. 7 - nota do tradutor.

${ }^{8}$ Cf. Heidegger, Sein und Zeit, trad. cit., §4, p. 23: "As ciências são modos de ser do Dasein em que este se conduz relativamente a entes que não necessitam ser [como] ele próprio. [...] As ontologias que têm por tema entes de um carácter de ser distinto do do Dasein têm, 
O que há nessa analítica do Dasein que sugira um «anticientismo»? Pouca coisa ou nenhuma. Mas que diz enfim essa analítica do Dasein acerca das ciências? Grosso modo, podemos afirmar que se limita a limitar, isto é, a dizer que a actividade científica e a sua produção de conhecimento e verdade, enquanto possibilidades do Dasein, são «derivadas». Vejamos.

Dissemos já que as ciências são um modo de abordar o ente, que tematizam e conceptualizam certos domínios do ente ou do ser. Todavia, a tematização ou conceptualização desses domínios efectua-se já a partir de uma experiência e de uma interpretação prévias. Heidegger adianta:

"Chamamos ciências positivas às ciências de um ente dado, de um positum; a sua caracterização reside no facto de a objectivação, do que elas tomam por tema, ir direito ao ente, enquanto ela [a objectivação] prolonga a atitude pré-científica já existente face ao ente."

As ciências não surgem ex nihilo, têm «condições de possibilidade», dependem de estruturas prévias. São actividades do Dasein (vulgo homem), e a investigação científica não é a única nem a mais imediata forma de ser possível do Dasein. ${ }^{10}$

Em Heidegger, falamos da estrutura «ser no mundo» como estrutura fundante da actividade científica e do conhecimento elaborado por esta: "O conhecimento é um modo de ser do Dasein enquanto "ser no mundo», tem o seu fundamento ôntico nesta "estrutura de ser»."11 Isto quer tão-somente

por conseguinte, os seus fundamentos e motivos na própria estrutura ôntica do Dasein, a qual encerra em si a determinação de uma compreensão pré-ontológica do ser. Assim, a ontologia fundamental, a única de onde podem surgir todas as mais, tem de ser buscada na analítica existenciária do Dasein".

${ }^{9}$ Heidegger, "Phaenomenologie und Theologie", trad. cit., p. 359. Heidegger não é o único a afirmar este carácter derivado da ciência. A «atitude pré-científica» pode ser pensada de modos diferentes: como forma de vida, como mundo vivido, como prática ou como interacção mediatizada pela linguagem, como background cultural, como tradição (a este propósito, cf. HABERMAS, "La redéfiniton du rôle de la philosophie" in Moralbewusstsein und Kommunikatives Handeln. Morale et communication, trad. Christian Bouchindhomme, Paris, Cerf, 1986, p. 31).

Heidegger, Sein und Zeit, trad. cit., §4, p. 21.

11 Heidegger, Sein und Zeit, trad. cit., $\$ 13$, p. 75. Num texto anterior a Sein und Zeit, Heidegger dirá que a atitude científica é uma modalidade, entre outras, da vida fáctica, modalidade que supõe já um mundo (vivido): "No cuidado do olhar dirigido para, da pura curiosidade (curiositas, cura), o mundo está presente, não mais como o negócio do trato em exercício, mas simplesmente como o aspecto que se oferece à vista na consideração. A consideração exerce-se como inspecção e determinação e pode estruturar-se a título de ciência. Esta é, por conseguinte, uma modalidade, temporalizada pela vida fáctica, da comsideração própria ao trato preocupado com o mundo. Enquanto mobilidade do trato assim definido, ela é um modo de ser da vida fáctica e contribui a aperfeiçoar a sua existência." (Heidegger, Phänomenologische Interpretationen zu Aristoteles. Interprétations Phénoménologiques d'Aristote, trad. J.-F. Courtine, Mauvezin, Trans-Europ Repress, 1992, pp. 21-22., itálico nosso) 
dizer que o nosso acesso ao ente não é primariamente «teórico», «científico». O ente não nos surge de raiz e na maior parte das vezes como «objecto» de conhecimento.

O nosso estar aí junto a algo no mundo não é, em princípio, um estar estupefacto a olhar para o ente, para objectos, para «entes em face». Estamos já aí com o ente, mas manejando-o, manipulando-o, usando-o; temos um «trato» com o ente. De um modo geral, não começamos por dizer 'a cadeira pesa 2,5kg' ou 'a cadeira é extensa' (proposições «teoréticas»), mas antes 'a cadeira serve para Y' e Y é uma tarefa do Dasein. Não começamos por conhecer, o que não quer dizer que não comecemos por descobrir já algo. Não estamos sempre a descobrir o ente por meio de predicados, mas estamos sempre já a cuidar de algo, ocupados com algo, pré-ocupados com algo e lançados numa possibilidade de ser que não tem necessariamente de ser a de conhecer. $^{12}$

O conhecimento será, então, uma possibilidade, entre outras, do Dasein, um modo peculiar de ver. Ao existirmos, existimos num mundo, junto ao ente, que compreendemos e interpretamos já de alguma maneira (quer dizer, de um modo não temático, não explícito). Há já uma significabilidade aberta no compreender. O compreendido é já acessível de tal maneira que se pode destacar nele o seu «enquanto que». Assim, por exemplo, uma cadeira surge-nos já como «cadeira», como algo que serve para. O trato com o ente «vê», interpreta, esse ente como disponível. Tal ver é antepredicativo (mas não antediscursivo), é interpretativo-compreensivo: insere o ente cadeira numa possibilidade do Dasein, quer dizer, compreende-o à luz dessa possibilidade (por exemplo, como ente de que o Dasein precisa para se sentar para escrever uma carta para que esta etc.). A cadeira surge como ente disponível, não surge necessariamente como sujeito de predicados. E para tomarmos o ente como sujeito de predicados, este deve estar já descoberto, visto, de alguma maneira $^{13}$. Há algo similar no trabalho propriamente científico.

12 Como indica Heidegger: "[...] o Dasein está sempre e já, em função da sua forma de ser primária, «aí fora» junto do ente que se encontra dentro do mundo, já descoberto de alguma maneira." Vide Heidegger, Sein und Zeit, trad. cit., §13, p. 73.

13 "A articulação do compreendido no aproximar-se interpretativamente dos entes, seguindo o fio condutor do "algo enquanto algo», é anterior a toda a proposição temática sobre eles.”(cf. Heidegger, op. cit., §32, p. 173. A proposição, como dissemos já, funda-se no compreender, é um modo derivado da interpretação, é o desenvolvimento de uma possibilidade projectada no compreender. Deste modo, diríamos que a tematização elaborada pelas ciências (tematização expressa em teorias, ou seja, enunciados) é um prolongamento da atitude pré-científica já existente face ao ente. Heidegger pensa a proposição destacando três níveis - a indicação, a predicação e a comunicação - que se deixam resumir na afirmação: "a proposição indica fundando-se no já aberto pelo compreender ou descoberto pelo «ver em redor»."(Heidegger, op. cit., §33, p. 181.) Retomemos o exemplo da cadeira para aludirmos à distinção entre logos apofântico (caracterizador do trabalho científico) e logos hermenêutico. Na proposição 'a cadeira pesa $2,5 \mathrm{~kg}$ ' visamos a cadeira enquanto sujeito de predicados, indicamos uma característica da e apenas da cadeira; o ver restringe-se aos li- 
As ciências descobrem o mundo através de teorias explicativas (causais) que consistem em proposições ou enunciados. Uma definição não tão formal de ciência diz-nos que: "A ciência pode definir-se como um conjunto de proposições verdadeiras conectadas por relações de fundamentação." ${ }^{14}$ Mas, perguntará o filósofo, quais as condições de possibilidade de algo como o enunciado ou a proposição? A analítica existenciária do Dasein fornece-nos uma resposta. A proposição é um modo derivado da interpretação e esta, por sua vez, funda-se no compreender, elemento crucial da estrutura «ser no mundo» entendido como projecção de possibilidades ou como o que constitui existenciariamente o «ver» (em sentido muito lato) do Dasein ${ }^{15}$.

A par com o carácter derivado do conhecimento científico vem o carácter derivado da «verdade», do «desvelar», próprio das ciências. A verdade tem, evidentemente, uma função decisiva no trabalho das ciências. A verdade, cujo «lugar natural» é a proposição ou o juízo, a verdade como adaequatio, é considerada também como algo derivado. Isto porque para que a adequação seja possível, é necessária uma verdade anterior a essa verdade proposicional ou predicativa. Na medida em que o conhecimento é conhecimento de, expresso em proposições sobre, isso de que se predica deve estar já manifesto de algum modo. Quer dizer, a verdade predicativa supõe um acesso veritativo face ao ente, um acesso antepredicativo ${ }^{16}$. A verdade não se

mites do que se diz. O que é indicado é a própria cadeira, esta torna-se tematicamente patente nesta sua determinação. O que se salienta é a cadeira e um atributo seu. Contudo, se dissermos 'a cadeira é dura', na maior parte das vezes 'é dura' significa 'é desconfortável', não visamos a resistência ou densidade da cadeira como algo material. Não estamos num nível predicativo. Nesta proposição não há uma estreiteza de conteúdo como na outra proposição; 'é dura' não é um atributo que reenvie apenas para a cadeira, mas antes para a cadeira enquanto serve para algo (para nos sentarmos). Nesta proposição ocorre um reenvio para fora da coisa, para uma possibilidade do Dasein: o ver não se restringe ao ente visto. A proposição descreve, interpreta, a cadeira enquanto está inserida num nexo de reenvios, enquanto está inserida num todo a partir do qual é compreendida e interpretada. A cadeira não é entendida como «substância», como algo sem relação ao mundo. As proposições têm as suas diferenças: ambas têm sentido, mas uma delas não é uma «proposição teorética».

14 Heidegger, Sein und Zeit, trad. cit., §4, p. 21. Esta definição, não completa, de ciência não parece divergir muito da que, por exemplo, é fornecida por Popper: "Sugiro que o objectivo da ciência seja o de encontrar explicações satisfatórias para o que quer que nos pareça precisar de explicação. Por explicação (ou explicação causal) entende-se um conjunto de proposições, no qual uma descreve o estado de coisas a explicar (o explicandum), enquanto as outras, as proposições explicativas, formam a «explicação» no sentido estrito do termo (o explicans do explicandum)." Popper, Objective Knowledge, Oxford, Clarendon Press, s.d., p. 191.

15 Cf. Heidegger, op. cit., p. 166ss.

16 Sobre a crítica ao conceito tradicional de verdade cf. por exemplo Sein und Zeit, §44. Esta problemática é explicitada em Vom Wesen des Grundes nos seguintes termos: " A concordância do nexo com o existente, e por conseguinte o seu próprio acordo, não tornam como tais o existente acessível. É necessário que este esteja já manifesto como «isso de que» é possível uma determinação predicativa; é preciso pois que ele seja anterior a essa predicação e para ela. Para ser possível, a predicação deve ter o seu lugar num acto de manifesta- 
restringe ao campo do juízo e, evidentemente, não é património exclusivo das ciências.

As ciências têm, então, o seu fundamento ôntico na estrutura «ser no mundo», estrutura fundante. Para que se constituam enquanto tal, necessitam de um momento pré-cursor, pré-científico, onde se esboce a possível tematização dos vários sectores que estudam.

Na experiência pré-científica está já presente uma compreensão dos domínios do ser. É dessa compreensão, veiculada por uma atitude pré-científica, não necessariamente «natural» e a que se pode chamar uma «lógica produtiva», que as ciências extraem os seus conceitos fundamentais. A ciência trabalha a partir de «pressupostos teóricos», tem já os seus «compreendidos», que problematiza e analisa.

Referimos algo que é anterior e decisivo para a investigação científica. Há um questionar que precede o questionar científico. Tal questionar, e a interpretação decorrente, criadora de conceitos, têm um carácter ontológico: elaboram uma interpretação da constituição fundamental do ser deste ou daquele domínio do ente. É um momento ontológico-filosófico, nele brotam conceitos fundamentais que são os fios condutores com que se abrem pela primeira vez e de uma maneira concreta os domínios do ente ${ }^{17}$.

ção que não tenha ele próprio um carácter predicativo. A verdade da proposição está enraizada numa verdade (um pôr a descoberto) mais elevada de origem, num estado manifesto do existente que é antepredicativo e a que chamamos verdade ôntica." (Heidegger, "Vom Wesen des Grundes". "Ce qui fait l'être-essentiel d'un fondement ou «raison»" in Questions I, trad. Henry Corbin, Paris, Gallimard, 1968, pp. 95-96.) A verdade como adequação não parece levantar grandes problemas aos cientistas ou aos epistemólogos, uma vez que a aceitam; Popper afirma: "Aceito a teoria do senso comum (defendida e aperfeiçoada por Alfred Tarski) segundo a qual a verdade é a correspondência com os factos (ou com a realidade); ou, mais precisamente, que uma teoria é verdadeira se e somente se corresponde aos factos" (Popper, op. cit., p. 44., itálico nosso). O que Heidegger simplesmente nos diz é que essa verdade não é a única e que depende de uma outra verdade. E não há, por parte de Heidegger, uma desconsideração por este tipo de verdade: "A caracterização da verdade como concordância, adaequatio, omoiosis, é, sem dúvida, muito geral e vazia. Mas tem algo de justo, se se mantém sem prejuízo nas mais heterogéneas exegeses do conhecimento, que é o que ostenta este relevante predicado" (Heidegger, Sein und Zeit, trad. cit., §44, p. 247).

Cf. Heidegger, Sein und Zeit, trad. cit., §3, p. 20.: "Conceitos fundamentais são aquelas determinações nas quais se alcança, do domínio de coisas que servem de base a todos os objectos temáticos de uma ciência, uma compreensão prévia e directiva de toda a investigação positiva. [...] Mas enquanto cada um destes domínios é uma promoção do próprio sector dos entes, essa indagação prévia e criadora de conceitos fundamentais mais não é que uma interpretação da constituição fundamental do ser desses entes. Essa indagação tem de ser anterior às ciências positivas, e pode sê-lo.” Esta interpretação constituiria as ontologias regionais propriamente ditas. O trabalho efectivamente científico (descrição e explicação de fenómenos, avaliação de hipóteses pela experimentação, etc.) não será, em rigor, uma ontologia regional, mas supõe o trabalho pré-cursor desta.

A perspectiva de Heidegger, sobre esse trabalho prévio à investigação positiva das ciências, não nos parece até muito afastada da de Kuhn: "A pesquisa efectiva raramente começa antes que uma comunidade científica pense ter adquirido respostas firmes a questões 
No entanto, não deixa de ser necessário, para a ontologia, considerar, criticamente, de que modo os conceitos fundamentais das ciências atingem o ser. Isto porque as ciências são ônticas, quer dizer, estudam «factos», limitam-se ao ôntico; com o trabalho propriamente científico perde-se de vista o carácter ontológico dos conceitos fundamentais. Por exemplo, «tempo», «espaço», «movimento», são problemas para as ciências, o que já não acontece quanto à essência do tempo, do espaço, do movimento, etc. A ontologia tem de ser crítica, pois não pode deixar que o trabalho científico desfigure, encubra, os seus começos filosóficos:

"O «facto» de que se ocupam as ciências - e isto implica designar o elemento de compreensão do ser que se encontra de facto incluído necessariamente nas ciências, tal como em qualquer outra relação ao existente - esse facto, não constitui uma instância de legitimação do a priori [...] mas apenas uma instrução possível, uma referência à constituição original do ser; uma referência que deve estar submetida a uma crítica permanente."18

A ontologia não estuda factos, não tem um objecto material: o ser não é um positum. A ser uma ciência, a ontologia não poderia ser uma ciência positiva; sendo filosofia não terá necessariamente de ser uma «filosofia da ciência». Ainda assim, a ontologia deve contemplar en passant, por assim dizer, as ciências, porque estas explicitam domínios do ser.

como as seguintes: quais são as entidades fundamentais de que o universo é composto? Como interagem estas umas com as outras e com os sentidos?" (Kuhn, Thomas S., The Structure of Scientific Revolutions, Chicago and London, The University of Chicago Press, 1996, pp. 4-5.) Estas «respostas firmes» corresponderiam ao ente «já descoberto e compreendido de alguma maneira». As ciências partem de pressupostos, de "visões do mundo»; como diz Kuhn: "A ciência normal, actividade na qual a maior parte dos cientistas gasta quase todo o seu tempo, é feita sobre a assunção de que a comunidade científica sabe como o mundo é" (op. cit., p. 5.). Pensamos que a filosofia pode fornecer, ou pelo menos contribuir para, esse esclarecimento prévio. Heidegger considera que o verdadeiro movimento das ciências é o da «revisão» dos conceitos fundamentais e que o nível de uma ciência se determina pela sua capacidade de experimentar uma crise dos seus conceitos fundamentais (Heidegger, Sein und Zeit, trad. cit., §3, p. 19.). Por seu lado, Kuhn admite precisamente a possibilidade de intervenção, por parte da filosofia, em momentos de crise: "Confrontados com uma anomalia, ou com a crise, os cientistas tomam uma atitude diferente face aos paradigmas existentes, e muda também a natureza da sua investigação. A proliferação de articulações rivais, a vontade de tentar qualquer coisa, a expressão de descontentamento explícito, o recurso à filosofia e ao debate sobre fundamentos, tudo isto são sintomas de uma transição da ciência normal para a pesquisa extraordinária” (op. cit., pp. 90-91., itálico nosso).

18 Heidegger, "Vom Wesen des Grundes". "Ce qui fait l'être-essentiel d'un fondement ou «raison»" in Questions I, trad. Henry Corbin, Paris, Gallimard, 1968, p. 99. 
No retorno à origem, à constituição originária do ser, a ontologia tem de ser crítica, «destrutiva» até ${ }^{19}$. A ontologia encontra criticamente as ciências, enquanto está a caminho de algo que as ciências não consideram.

\section{As ciências, a técnica e o «outro pensar»}

O estar contra as ciências parece ser mais evidente no pensamento do «segundo» Heidegger, quando este pensa a questão da técnica. Ainda assim, existem, antes dessa «viragem», algumas referências menos simpáticas a propósito da ciência ${ }^{20}$.

A ciência é seguramente um fenómeno essencial dos nossos tempos. Vivemos na «era da ciência». Contudo, ela destacou-se de tal maneira que parece ter acabado (com) a filosofia.

Desde a época dos gregos, um traço da filosofia ficou claro: o desenvolvimento das ciências no interior do horizonte aberto pela filosofia. O desenvolvimento das ciências vai a par com o estabelecimento da sua auto-suficiência, da sua libertação face à filosofia. Ninguém poderá negar que as ciências arrebataram certas questões à filosofia, acabando por as esclarecer e resolver com relativo sucesso. Esse fenómeno contribuiu para o acabamento da filosofia:

"A filosofia torna-se ciência do homem, ciência fundada sobre a experiência de tudo o que pode, para o homem, tornar-se objecto da técnica, pela qual ele se instala no mundo ao elaborá-lo segundo os múltiplos modos das fabrica-

19 Cf. Heidegger, Phänomenologische Interpretationen zu Aristoteles, trad.cit., p. 31. e Sein und Zeit, trad.cit., \$6. Num texto preparatório de Ser e Tempo, Heidegger explicita melhor essa relação crítica entre filosofia (ontologia) e ciências, dizendo até que a ontologia deve «dar um salto» sobre as ciências: "[...] a filosofia destas ciências [...] pretende: 1) fornecer a fundação da sua génese a partir da experiência pré-teorética, 2) manifestar o modo de acesso que têm à realidade pré-dada e 3) especificar o modo de formação de conceitos que advém em tal investigação. Porque a realidade - a natureza e a história também - só podem ser acedidas, em certo sentido, saltando sobre as ciências; esta sua abertura pré-científica - filosófica até - torna-se o que chamo uma lógica produtiva, uma abertura antecipatória e uma penetração conceptual de potenciais domínios de objectos para as ciências" (Heidegger, Prolegomena zur Geschichte des Zeitbegriffs, trad. cit., p. 2., sublinhado nosso).

Por exemplo: "O homem que não filosofa, inclusive o homem de ciência, existe certamente, mas dorme. Só o filosofar é o Dasein desperto"(Heidegger, Die Grundbegriffe der Metaphysik. Welt-Endlichkeit-Einsamkeit, trad. cit., p. 47.). A observação não é decerto simpática; todavia, Heidegger não é o único filósofo a fazê-la: "O homem tem de despertar para o espanto - e talvez também os povos. A ciência é um modo de os adormecer novamente" (Wittgenstein, Vermischte Bemerkungen. Culture and Value, trad. Peter Winch, Oxford, Basil Blackwell, 1980, p. 5e.). 
ções que o caracterizam. Tudo isso se realiza sobre a base e segundo as normas da exploração científica de todos os sectores do ente." 21

O predomínio do pensar que calcula é o acabamento legítimo da filosofia que se desvanece por entre as ciências. O que se pergunta é se haverá então possibilidade para um outro pensar.

Difícil possibilidade. Difícil se pensarmos que vivemos uma indigência de pensamento, diz Heidegger. A falta de pensamento é um inquietante hóspede que se aloja no mundo dos nossos dias ${ }^{22}$. Falta de pensamento: afirmação escandalosa. Como pode haver uma falta de pensamento se se fazem tantos planos, estudos, investigações? Certamente, esse pensar, o pensar que calcula, abunda e é de um grande proveito; é um pensar que permanece, para nós, indispensável ${ }^{23}$. Não é esse o pensar que falta. O pensar que falta é um pensar que não manipula, que não domina simplesmente, mas que medita.

Esse é o problema da ciência actual e do pensar que a caracteriza. Ao invés da ciência antiga, a ciência actual é uma ciência que se aplica à realidade e a transforma através da técnica. É uma ciência que manipula, «domina»; característica patente na seguinte metáfora:

"As teorias são redes lançadas para apanhar isso a que chamamos «o mundo»: para o racionalizar, explicar e dominar."24

A ciência dos nossos dias já não é theoria, não é ciência "pura», desinteressada. Tornou-se «útil» e possivelmente destrutiva. Não é mais aquela ciência de que nos fala Aristóteles:

21 Heidegger, "Das Ende der Philosophie und die Aufgabe des Denken". "La fin de la philosophie et la tâche de la pensée" in Questions $I V$, trad. Jean Beaufret et François Fédier, Paris, Galimard, 1976, pp. 115-116. Ou como é dito na entrevista ao Der Spiegel: "Os papéis que a filosofia desempenhava até agora foram hoje assumidos pelas ciências”(«Já só um Deus nos pode ainda salvar» in Filosofia, vol. III, n. ${ }^{\circ} 1 / 2$, trad. Irene Borges Duarte, Lisboa, Sociedade Portuguesa de Filosofia, 1989, p. 123.). Entre as ciências e a filosofia estabeleceu-se uma perigosa familiaridade; as diferenças esbateram-se: o que dantes identificava e distinguia a filosofia (a reflexão, o trabalho de fundamentação, a «analítica da finitude», etc.) passou a ser um traço característico de algumas ciências - as ciências humanas ou as «ciências sistemáticas da acção»(a este propósito cf. Foucault, Les Mots et les Choses, Paris, Gallimard, 1997, p. 363 ss., Habermas, Technik und Wissenschaft als Ideologie. Técnica e ciência como ideologia, trad. Artur Morão, Lisboa, Edições 70,s.d., p. 139ss. e Habermas, "Retour à la métaphysique?" in Nachmetaphysisches Denken, Philosophisch Aufsätze. La pensée postmétaphysique, Essais philosophiques, trad. Rainer Rochlitz, Paris, Armand Colin, 1993, p. 45 ss.).

Cf. Heidegger, "Gelassenheit", trad. cit., p. 163.

Cf. Heidegger, op. cit., p. 165.

24 Popper, The Logic of Scientific Discovery, London, Hutchinson, 1977, p. 59, itálico nosso. 
“[...] se é para escapar à ignorância que o homem estuda a filosofia, então é óbvio que o homem persegue a ciência devido ao conhecimento e não por uma utilidade prática" (Metafísica, 982 b 11 ss.).

A ciência actual não tem mais como objectivo "a sua própria realização". A crítica de Heidegger aponta neste sentido: o pensar que calcula não pode ser o único pensar, pois é um pensar que leva ao esquecimento do que é essencial. Ao limite, é um pensar que não pode pensar o essencial. O que é necessário é abrir outras vias de pensamento.

Devemos confessar que não nos é explícito em que consiste esse outro pensar nem tão-pouco o que será esse «essencial» que tal pensar deve pensar. A tarefa desse pensar, não mais filosófico, tem o carácter de uma «preparação», e não o de uma fundamentação; pretende dispor-nos a escutar algo que, do fundo dos tempos, permanece impensado. É como que um prelúdio a não sabemos bem o quêt $\hat{e}^{25}$.

Mas, pensando com Heidegger contra Heidegger, se tal pensar já não é filosofia, então talvez possamos dizer que esse pensar é o pensar de quem «dorme».

É na distinção entre pensar que medita e pensar que calcula que a acusação de anticientismo aparentemente se funda. E parece estar condensada na afirmação: «a ciência não pensa». Isto é certamente dito por Heidegger. Mas não é só isto que é dito. Consideremos o contexto em que surge esta afirmação:

“[...] a ciência não pensa. Ela não pensa porque o seu procedimento e os seus meios auxiliares são tais que ela não pode pensar - pensar à maneira dos pensadores. Que a ciência não possa pensar, não é preciso ser visto como um defeito, mas antes como uma vantagem. Só essa vantagem assegura à ciência um acesso possível a domínios de objectos que respondem aos seus modos de investigação; só essa vantagem permite o seu estabelecimento."26

${ }^{25}$ Cf. Heidegger, «Já só um Deus nos pode ainda salvar», pp. 122-123. Este pensar é «quase religioso», esse impensado «essencial», que não sabemos bem o que é, pode ser um deus: "Como única possibilidade, resta-nos preparar pelo pensamento e pela poesia uma disposição para o aparecer do deus ou para a ausência do deus em declínio" (Heidegger, op. cit.,p. 122.). Ou como declara noutro texto: "É a alma que fala? É o mundo? É deus? Tudo diz a renúncia que conduz para o Mesmo" (Heidegger, "Der Feldweg". "Le chemin de campagne" in Questions III, ed.cit., pp. 14-15.).O que nos leva a afirmar que este Heidegger está nos antípodas de um outro Heidegger: "Ao interpretar ontologicamente a realidade humana como ser-no-mundo, nada se decide, nem em sentido positivo, nem em semtido negativo, sobre uma possibilidade de ser-em-relação a deus" (Heidegger, "Vom wesen des Grundes", trad.cit., p. 136., itálico nosso). A aceitar este «outro pensar», já não penasmos o «ser no mundo». Há então uma demissão face à realidade humana? Se «já só um deus nos pode ainda salvar», o Dasein é «impotente». trad. cit., p. 157., itálico nosso. O pensamento que calcula, ao invés do pensamento que 
E, portanto, a ciência pensa, quer dizer, calcula. Só não pensa, medita, à maneira dos pensadores. Não há aqui anticientismo algum.

Pelo que expusemos muito brevemente, pensamos que o famoso anticientismo de Heidegger é um mal-entendido. Apesar de criticar o «cientismo», Heidegger não é contra as ciências, tal como não é contra a técnica. Será porventura exagerado considerar que Heidegger sofre de «tecnofobia». Pois, como afirma o próprio, a técnica não é algo diabólico, é algo indispensável e querer abdicar dela é prova de miopia ${ }^{27}$. A fortiori, o mesmo se poderá dizer das ciências. Todavia, podemos dizer que Heidegger é contra as ciências, mas há que compreender bem o sentido desse 'contra'.

Num primeiro momento abordámos uma perspectiva, ou uma tentativa, um tanto ou quanto clássica de «fundamentação». A filosofia, enquanto ontologia fundamental, relaciona-se criticamente com as ciências, demarca-se destas, quer dizer, mantém a sua identidade e diferença. Que entender então por «crítica»?

Recuperando umas palavras de Heidegger acerca da crítica kantiana, talvez possamos afirmar que: "«Crítica» [...] designa a acção de colocar o que em toda a posição deve ser colocado como prévio enquanto determinante e decisivo." 28 A ontologia fundamental, a analítica do Dasein, tenta mostrar, justamente, o que é determinante e decisivo: as estruturas fundantes; isso que possibilita, por exemplo, algo como a investigação científica.

Num segundo momento, o que se afirma é a necessidade de criticar a primazia das ciências, a necessidade de estar contra as ciências, de haver um outro pensar: um pensar "contrário» ao das ciências; e, enquanto tal, esse pensar que medita necessita do pensar que calcula, pelo menos para manter a sua própria identidade e diferença. Isto é: não pode querer acabar com o pensar que calcula. Assim, o pensar contra expressa uma atitude crítica, não uma aversão ou um pensamento que queira acabar com as ciências. Mas «crítica» já não significa completamente essa "acção de colocar o que em toda a posição deve ser colocado como prévio enquanto determinante e decisivo": o pensar que medita já não é filosofia.

O pensar que medita parece procurar também o determinante e decisivo. Contudo, o pensamento do «segundo» Heidegger é um tanto ou quanto os-

medita, tem a vantagem de não se questionar a si próprio. Essa vantagem é reconhecida por Kuhn quando sustenta: "Por exemplo, já notámos que a recepção de um paradigma comum liberta a comunidade científica da necessidade constante de reexaminar os seus primeiros princípios, e que isso permite aos membros dessa comunidade concentrarem-se exclusivamente nos fenómenos mais subtis e esotéricos que lhes interessam. Inevitavelmente, isso aumenta quer a competência quer a eficiência com que o grupo como um todo resolve novos problemas" (Kuhn, op. cit., pp. 163-164., itálico nosso).

Vide Heidegger, “Gelassenheit”, trad. cit., p. 176. 
cilante e incoerente, por vezes, com o do «primeiro». Por um lado, salienta os perigos da técnica e o que nos pode salvar ("onde cresce o perigo cresce também o que salva"). A sua crítica sugere a necessidade de alternativas. Por outro lado, a alternativa proposta não é filosófica. Face ao perigo confuso, nocivo, da produção filosófica, enaltece-se a proximidade do salutar perigo do poeta que canta ${ }^{29}$. Anuncia-se um pensar poético, «lento», um pensar que escuta o ténue apelo do ser, da origem; um quase religioso pensar que, face ao predomínio da técnica e do cálculo, chega a declarar: "já só um deus nos pode ainda salvar". Desta maneira, que se expressa senão um «nós próprios já nada podemos fazer», uma certa «impotência», a impotência de um ente, outrora insigne, que espera o aparecer ou o desaparecer de um deus? E se pensarmos que nessa declaração há uma certa «esperança», então talvez possamos dizer que o esperançado filósofo (?) não se encontrava já na sua mais radical singularidade.

\begin{abstract}
In this paper we deal with a not so slight misunderstanding about Heidegger's conception of science(s). We try to show that instead of a so-called «anti-scientism» we find rather a critical thought on the part of Heidegger. Critical in two senses: one that implies a questioning and an explicitation of the pre-scientific, non-scientific foundations (or conditions) of science and the analysis of the relation between sciences as «regional ontologies» and philosophy as «fundamental ontology»; another that suggests the «need of another thinking», an alternative (certainly discussible) to the predominant calculative thinking of «the era of science».
\end{abstract}

29 Cf. Heidegger, "Aus der Erfahrung des Denkens" "L'Expérience de la pensée" in Questions III, trad. André Préau, Paris, Gallimard, 1966, p. 29. 